\title{
Modeling the 'Second' Soil Erosion on Non-Paved Roads
}

\author{
Twaibu Semwogerere, Samuel B. Kucel, and Peter O. Lating
}

\begin{abstract}
A mathematical model is constructed to describe erosion from the features formed after the 'first' erosion on gravel or dirt roads. The model was based on parameters such as the nature or make of the road, erosion effect, and the effect of repairs. The rill/dune effects on the road were assumed to be proportional to the repairs that are necessary to neutralize them. The repairs model was first analyzed then the general erosion model. Finally, an erosion model that combines all the parameters was developed and analyzed with a numerical example. The main methods used included experimental designs and numerical techniques for the formulation and analysis. Results show that the approximate time required for road repairs given a remarkable effect, reduces with the size of the initial effect. A bigger initial effect reduces the time required to initiate a repair on such roads. Results further showed that erosion effects resulting from the rill/dune development effects are tremendously reduced. Once correct measurements are taken and historically followed, good road maintenance may be experienced in order to enhance economic development in developing countries.
\end{abstract}

Index Terms -Erosion, features, model, repairs, rill, dune.

\section{INTRODUCTION}

Various approaches to water erosion and deposition modeling have been developed in the recent decadesto predict the rates of soil erosion and sediment deposition over particular landscapes [1]. The main types of models developed were of material and mathematical formulations. Material models represent the physics of the system being modeled and mathematical models are normally classified as empirical or process-based [2]. The first models on erosion were empirical and developed primarily from statistical analysis of erosion data. However, recent models have been based on equations that describe the physical, biological, and chemical processes that affect soil erosion [3].The dimensional classification was outlined basing mainly on erosion by river flows. They included: three-dimensional, two-dimensional and one-dimensional. Other types of erosion modeling were similarly classified in the same way but with different approaches [4]. Sediment models are also classified as steady-state or unsteady-state, coupled or uncoupled, equilibrium or un-equilibrium, and uniform or non-uniform models [3]. The focus of this paper was on steady and the unsteady states. A model is steady if the flow

Manuscript received March 18, 2014; revised May 18, 2014.

T. Semwogerere is with the College of Engineering Design Art and Technology (CEDAT), Makerere University. P. O. Box, 7062, Kampala, Uganda (e-mail: semwogereretwaibu@yahoo.co.uk).

S. B. Kucel is with the Mechanical Engineering Department, Makerere University. P. O. Box, 7062, Kampala, Uganda (e-mail: sbkucel@gmail.com).

P. O. Lating is with the Department of ICT, CEDAT, Makerere University. P. O. Box, 7062, Kampala, Uganda (e-mail: plating@tech.mak.ac.ug). and sediment conditions in a model are constant; otherwise it is unsteady [4].

One of the most important and affected landscape is the unpaved surface of the road. Yet, roads involve one of the most risky parts of human transport in the world. More so the unpaved roads support the biggest percentages of income for most economies in the developing countries. Existing models do not specifically look at the features formed on erosion paths, and the unsteady state terms are ignored when it comes to numerical examples [5]. Similarly modeling erosion on gravel roads is a recent study which still needs attention. In fact erosion on roads is managed through the various road designs which are fixed for some but most important issues in sediment flow [5]. Therefore it is one of the newly found area of managing erosion on roads through mathematical modeling.

Thus the main objective of this paper was to basically model erosion on gravel or dirt roads. The specific model was in regard to the 'second' erosion after some initial erosion or 'first' erosion on the road surface.

\section{Methodology}

\section{A. Experimental Layout and Design}

This study used the quantitative methods which basically involved experimental designs. The paper involved developing a model for the "second" erosion on non-paved roads. It also focused on accelerated erosion type that occurs when such roads are constructed. The total number of roads that were experimented was eight and was selected from the Eastern, Central, Western, and Northern Uganda. Various spots were identified on these roads for possible experimentations [5].

In addition the study focused on the national roads category and design classes. Sections of the roads not exceeding one hundred meters, but carefully selected to include features of interest were considered. The features considered were mainly the dunes and rills. Road dunes that were considered were those that form in the drainage systems or water channels on the sides of the roads. Parabolic dunes are common in erosion paths and were the main focus of this paper [6], [7].

The rills considered were those that form on the roadside channels and are designed in the construction process and later formatted by sediment flow. For the rill or gorge, the study considered narrow and shallow gorges (rills) between $0.05 \mathrm{~m}$ and $7.5 \mathrm{~m}$ wide and not exceeding $12.5 \mathrm{~m}$ depth, for experimentations [5]. The paper also considered modeling that may disregard the chemical composition of the components used to construct these roads and focused on national roads.

The experiments done included extracting and determination road soil types, identification and measuring 
effects of erosion features (dunes and rills), gradation tests (sieve analysis), AASHO classifications liquid limit, plastic limit, plasticity index, and linear shrinkage [6]-[9].

Natural rain was the focus for most field experiments. In fact some experiments like runoff speed of sediments were done during rainy seasons for the given regions. In this case, the effects were the experimental factors, and the various features were the experimental units. However, rainfall and run off simulation were also possible for the experiments that could have fallen under the dry seasons.

Quasi experimental designs and non-randomized complete block design, which is somehow similar to stratified sampling, were also applicable. The strata in this case were taken as the region from which the study focused on the dirt roads. The block was that part of the dirt road of at most 100 m. The blocks were simulated from erosion plots as illustrated by various authors like Morgan [10]. In this study, the blocks comprised of that part of the gravel road with the various features of interest. This study used at most four blocks for each region. The study used the observation design techniques to observe already formed features.

\section{B. Data Collection, Analysis and Interpretation Methods}

The experimental data was collected depending on the rains in the given regions and on the experiment days selected by both the researcher and field assistants. Various measurements were taken and recorded in tables and other soft archives for further handling.

On the other hand, the collected data was analysed by simple comparisons from some renown and developed model parameters [6], [7]. The model was validated using the data collected. Computer software like, Stata11 were briefly used in the model testing, evaluation, and analysis. Finally data was analyzed by the comparative study approach.

\section{FINDINGS}

\section{A. Model Parameters and Basic Assumptions}

This paper was based on the findings from the experiments done in the field and in the laboratory. The parameters used in the construction of the conceptual model mainly focused on the features formed by erosion on gravel roads. The model took in to account the rate of development of simple rills on the road to big rills or even gorges. It also considered the rate of deterioration of constructed drainage channels [5], as rills eat them up. The deterioration of the road side drainage channels should also cater for the dunning (blocking) of the channels or enlarging rills (road squeezing). The model is a one-dimensional model with mathematics, physics, hydrology, and geo-engineering as the main subjects. Its main applications are expected to be decision making in road construction and maintenance, and further research. The following were the parameters: nature or make of the structure $(M)$, size of channels (erosion paths) $\left(\boldsymbol{S}_{c}\right)$ (the volume, velocity [11], [12], density of sediment flow was considered and no chemical composition was considered in this paper), and the repairs (or maintenance) $(p)$

Therefore the proposed model for erosion on gravel roads was a function of these parameters:

$$
\xi=f\left(M, S_{c}, p\right)
$$

The main parameters $M$ and $S_{c}$ in equation (1) were already modeled in [6], [7]. The parameter $p$ was modeled and analyzed in this study and finally worked out for the entire model in equation (1) above. This paper aimed at developing a numerical model for the simulation of unsteady state flow by varying the modeling parameters to the main parameters.

\section{B. Modeling Parameters}

The nature or make of the structure included the soil type, design standards, and sediment type. It also took in to account the strength of flow, sediment size, volume, and density issues [1], [6], [7], [11], [13], [14]. The main design standard that was considered was on the roadway width with respect to the effects caused by rills and dunes development along the drainage paths affected by some erosion.

TABLE I: ROAD DESIGN STANDARDS BY UGANDA NATIONAL ROADS AUTHORITY (UNRA) [15]

\begin{tabular}{|c|c|c|c|}
\hline $\begin{array}{l}\text { DESIGN CLASS } \\
\text { (Gravel Surfaced) }\end{array}$ & $\mathbf{A}$ & B & $\mathbf{C}$ \\
\hline Capacity[pcu x 1000/day] & $4-8$ & $2-6$ & - \\
\hline Road-Way width (m) & 10 & 8.6 & 6.4 \\
\hline Speed & $\begin{array}{l}40-\mathrm{C} \\
\mathrm{mou}\end{array}$ & $\begin{array}{l}\text { for } \\
\text { ondit }\end{array}$ & ling \\
\hline
\end{tabular}

Although there may be more issues on the road surface for consideration as seen in Table I, the study focused on road-way width mainly and the rate at which erosion reduces the standard road size. The capacity and speed were not considered for this formulation although they can be used only in terms of the minimum and maximum road use required for the minimum destruction.

\section{1) The repairs / maintenance equation}

Gravel roads require much more frequent maintenance than paved roads [16]. Wheel motion shoves material to the outside and in between the travelled lines leading to rutting, reduced water run-off and eventual road destruction if unchecked by repairs and maintenance [17]. Simple grading is enough for maintenance as long as the deteriorating process is interrupted early enough.

The level and speed of response to destruction vary depending on various factors that include among others: the position of the road in the hierarchy, the budget available, and the scale and location of the fault. Maintenance of roads in Uganda varies from road to road based on factors mentioned earlier.

It was noted that the repairs were averagely done either by slashing on the sides of the road or use of hoes especially in the north western region of Uganda. It was also done by use of other designated machines for the case of gravel roads managed by UNRA. The average time of repairs noted was about twenty four months for UNRA-managed roads, and about eight months for Local Government (LG)-managed roads. The main reasons behind these timings were found to be that UNRA-managed unpaved roads are somewhat repaired to some level of standards than the LG-managed roads. They therefore take some time before real damage is 
realized.

In this study, the optimality aimed at was that the repairs or maintenance rate parameter should be inversely proportional to the time factor requirement necessary to take action in terms of maintenance. Therefore less time factor requirement was necessary for an increasing repair factor. The bigger the destruction factor through rilling or duning, the less the time required to engage a repair. Therefore,

$$
\frac{d p}{d t} \gamma \frac{q t+\alpha}{\tau_{c}\left(1+k_{e} C_{i} \tau\right)}, \alpha=c \tau_{c}
$$

where $C_{i}=$ compaction factor, $P=$ repair factor, $t=$ time effect, $q=$ flow rate/discharge rate, $K_{e}=$ erodibility parameter, $\tau=\tau_{o}-\tau_{c} ; \tau_{c}=$ critical shear strength, $\tau_{o}=$ shear strength, $c=$ integration constant and $\alpha=$ initial rill/dune size after some erosion.

The right-hand side of equation (2) was developed earlier when solving the rill and dune models in [6] and [7] (see equation (7)). Equation (2) was evaluated to the following equation:

$$
p=\frac{{ }^{k} \tau_{c}}{\alpha(t+1)}
$$

$k$ is the proportionality constant which was also crucial in determining the time required to initiate repairs or maintenance schedules. It was also noted that the repair factor was a function of time required to initiate a repair or in which a particular effect can occur. It also depends on the initial effect of erosion or deposition on the road, and the critical shear stress that affects the sedimentation flow conditions [18]. The $k$ values were evaluated for the initial effect which was considered also as the affected area $\alpha$ with $\tau_{c}$ and $t$ held constant as seen in the Table II:

TABLE II: $S_{c}$ VALUES FOR THE VARIABLES $t$ AND $c_{i}[6]$

\begin{tabular}{cccc}
\hline$\alpha\left(\mathrm{m}^{2}\right)$ & Time, $\boldsymbol{t}(\mathrm{s})$ & $\begin{array}{c}\text { Dry Density, } \\
\boldsymbol{C}_{i} .\left(\mathrm{kg} / \mathrm{m}^{3}\right)\end{array}$ & $\begin{array}{c}\text { Specific Volume for Rill } \\
\left.\text { Development, } \boldsymbol{S}_{c} \mathrm{~m}^{3} / \mathrm{kg}\right)\end{array}$ \\
\hline 0.0213 & 0 & 0 & 0.00375 \\
0.0213 & 5400 & 1757.6 & 0.00019 \\
\hline
\end{tabular}

Therefore for $\tau_{c}=5.68$, and $P=0.00019, k$ was evaluated as 0.0038482 , to give the following relationship

$$
p=\frac{0.004 \tau_{c}}{\alpha(t+1)}
$$

On the other hand, the area effect from the values in Table III were used in the evaluation of $k$ :

TABLE III: RILL SIZES VERSUS ROADWAY WIDTH FOR VARIOUS RAIN

\begin{tabular}{lllll}
\multicolumn{5}{c}{ SEASONS [5] } \\
\hline $\mathbf{F}_{\mathbf{1 i}}$ - Rills & $\begin{array}{c}\text { Width Difference } \\
(\boldsymbol{R} \boldsymbol{w} \boldsymbol{d})(\mathrm{m})\end{array}$ & $\begin{array}{l}\text { Height } \\
\text { Difference } \\
(\boldsymbol{R} \boldsymbol{R} \boldsymbol{d})(\mathrm{m})\end{array}$ & $\begin{array}{l}\text { Road } \\
\text { width }(\mathrm{m})\end{array}$ & $\begin{array}{l}\text { Rain } \\
\text { Days }\end{array}$ \\
\hline $\mathbf{F}_{\mathbf{1 1}}$ & 0.1016 & 0.1778 & 6.4 & 74 \\
& 0.1016 & 0.2845 & 6.4 & 22 \\
& -0.0635 & 0.0203 & 6.4 & 25 \\
& 0.1397 & 0.0279 & 6.4 & 16 \\
& 0.1016 & 0.0 & 6.4 & 4 \\
\hline
\end{tabular}

From Table III, a total of 141 rain days gave an area effect of up to $\alpha=0.1945005 \mathrm{~m}^{2}$ or $0.00138 \mathrm{~m}^{2}$ per day. This gave $p$ $=0.003049527$ and $\mathrm{a} k=0.000685516$, Therefore

$$
p=\frac{0.0007 \tau_{c}}{\alpha(t+1)}
$$

Equation (4) and (5) gave rise to the following evaluations (Table IV):

TABLE IV: REPAIR VALUES VERSUS THE TIME FACTOR REQUIREMENT FOR DIFFERENT $k$ AND $\alpha$ VALUES RESULTING FROM THE RILL EXPERIMENTS

\begin{tabular}{lccll}
\hline$k$ & $\alpha\left(\mathrm{m}^{2}\right)$ & $\mathcal{\tau}_{c\left(\mathrm{~N} / \mathrm{m}^{2}\right)}$ & $|p| \mathrm{m}^{3} / \mathrm{kg}$ & $t(\mathrm{~s})$ \\
\hline 0.004 & 0.021300 & 5.86 & $1.9 \times 10^{-4}$ & $5.4 \times 10^{3}$ \\
& & & $6.6 \times 10^{-6}$ & $1.62 \times 10^{5}$ \\
& & $4.4 \times 10^{-6}$ & $2.43 \times 10^{5}$ \\
0.0007 & 0.00138 & & $2.2 \times 10^{-6}$ & $4.86 \times 10^{5}$ \\
& & & $1.9 \times 10^{-4}$ & $5.4 \times 10^{3}$ \\
& & & $6.3 \times 10^{-6}$ & $1.62 \times 10^{5}$ \\
& & & $4.2 \times 10^{-6}$ & $2.43 \times 10^{5}$ \\
& & & $2.1 \times 10^{-6}$ & $4.86 \times 10^{5}$ \\
\hline
\end{tabular}

The repair factor was evaluated as a density or some degree of compactness required in suppressing a given destruction. A repair factor or damage of $6.6 \times 10^{-6} \mathrm{~m}^{3} / \mathrm{kg}$ required or was catered for after 30 rain days and that of $2.2 \times 10^{-6} \mathrm{~m}^{3} / \mathrm{kg}$ required a maximum of 90 rain days. Or a compaction of up to $6.6 \times 10^{-6} \mathrm{~m}^{3} / \mathrm{kg}$ was required for a damage of up to 30 rain days for a given $\tau_{c}$ and $\alpha$.

Similarly, from experiments regarding the dune, the $k$ values were also evaluated for the initial affected area $\alpha$ with the two $\tau_{c}$ valuesand $t$ held constant as seen in the table below:

\begin{tabular}{ccccc}
\multicolumn{5}{c}{ TABLE V: $S_{c}$ VALUES FOR THE VARIABLES $t$ AND $c_{i}$} \\
\hline $\begin{array}{c}\boldsymbol{\tau}_{c} \\
\left(N / m^{2}\right)\end{array}$ & $\alpha\left(\boldsymbol{m}^{2}\right)$ & $\begin{array}{c}\text { Time, } \\
\end{array}$ & $\begin{array}{c}\text { Dry Density, } \\
\boldsymbol{C}_{i} .\left(\mathrm{kg} / \mathrm{m}^{3}\right)\end{array}$ & $\begin{array}{c}\text { Specific Volume } \\
\text { for Dune } \\
\end{array}$ \\
& & & & $\begin{array}{c}\text { Development, } \boldsymbol{S}_{c} \\
\left(\mathrm{~m}^{3} / \mathrm{kg}\right)\end{array}$ \\
\hline 47.99 & 0.1265 & 5400 & 1654 & $-4.4192 \times 10^{-5}$ \\
& 0.1045 & & & $-2.877 \times 10^{-6}$ \\
0.04 & 0.1265 & 5400 & 1654 & $7.38749 \times 10^{-6}$ \\
& 0.1045 & & & $6.90176 \times 10^{-6}$ \\
\hline
\end{tabular}

TABLE VI: DUNE SIZES VERSUS ROADWAY WIDTH FOR VARIOUS RAIN

\begin{tabular}{lllll}
\multicolumn{5}{c}{ SEASONS [5] } \\
\hline $\mathbf{F}_{2 \mathbf{i}}-$ & $\begin{array}{c}\text { Width Difference } \\
\text { Rills }\end{array}$ & $\begin{array}{l}\text { Height Difference } \\
(\boldsymbol{R} w \boldsymbol{d})(\mathrm{m})\end{array}$ & $\begin{array}{l}\text { Roadway } \\
\text { width }(\mathrm{m})\end{array}$ & $\begin{array}{l}\text { Rain } \\
\text { Days }\end{array}$ \\
& & & & \\
\hline $\mathbf{F}_{\mathbf{2 1}}$ & 0.9398 & 0.0762 & 6.4 & 74 \\
& 0.1778 & 0.0178 & 6.4 & 22 \\
& 0.0635 & -0.0051 & 6.4 & 25 \\
& 0.0254 & 0.0076 & 6.4 & 16 \\
& 0.0381 & 0.0051 & 6.4 & 4 \\
\hline
\end{tabular}

Therefore Table $\mathrm{V}$ similarly resulted in the following relationships for the two $\tau_{c}$ values:

$$
\begin{gathered}
p=\frac{-0.00003 \tau_{c}}{\alpha(t+1)} \\
p=\frac{-0.0006 \tau_{c}}{\alpha(t+1)} \\
p=\frac{97384.6 \tau_{c}}{\alpha(t+1)} \\
p=\frac{12618.2 \tau_{c}}{\alpha(t+1)}
\end{gathered}
$$


On the other hand, the area effect from the values in the Table VI were used in the evaluation of $k$.

The different $k$ values gave rise to different $p$ values for a given time factor of up to three months or 90 days.

TABLE VII: REPAIR VALUES VERSUS THE TIME FACTOR REQUIREMENT FOR DIFFERENT $k$ AND $\alpha$ VALUES RESULTING FROM THE DUNE EXPERIMENTS

\begin{tabular}{lllll}
\hline$k$ & $\alpha\left(m^{2}\right)$ & $\mathcal{\tau}_{c\left(N / m^{2}\right)}$ & $|p| m^{3} / \mathrm{kg}$ & $t(\mathbf{s})$ \\
\hline-0.0003 & 0.1045 & 47.99 & $2.9 \times 10^{-6}$ & $5.4 \times 10^{3}$ \\
& & & $9.5 \times 10^{-8}$ & $1.62 \times 10^{5}$ \\
& & & $6.4 \times 10^{-8}$ & $2.43 \times 10^{5}$ \\
\hline-0006 & 0.1265 & 47.99 & $4.4 \times 10^{-5}$ & $5.4 \times 10^{3}$ \\
& & & $1.4 \times 10^{-6}$ & $1.62 \times 10^{5}$ \\
& & & $9.4 \times 10^{-7}$ & $2.43 \times 10^{5}$ \\
\hline 97384.6 & 0.1045 & 0.04 & $4.7 \times 10^{-7}$ & $4.86 \times 10^{5}$ \\
& & & $2.3 \times 10^{0}$ & $5.4 \times 10^{3}$ \\
& & & $1.5 \times 10^{-1}$ & $1.62 \times 10^{5}$ \\
& & & $7.7 \times 10^{-2}$ & $4.86 \times 10^{5}$ \\
\hline 126183.2 & 0.1265 & 0.04 & $7.4 \times 10^{0}$ & $5.40 \times 10^{3}$ \\
& & & $2.5 \times 10^{-1}$ & $1.62 \times 10^{5}$ \\
& & & $1.6 \times 10^{-1}$ & $2.43 \times 10^{5}$ \\
& & & $8.2 \times 10^{-2}$ & $4.86 \times 10^{5}$ \\
\hline
\end{tabular}

\section{2) The erosion model}

The equation was constructed through combining equations (3) and equation (7) below:

$$
S_{c}=\frac{q t+\alpha}{\tau_{c}\left(1+k_{e} c_{i} \tau t\right)}
$$

This rill/dune equation (i.e (7)) developed in [6], [7] predicted the effects of erosional dunes and rills on gravel roads. It was modeled in such a way that it predicts erosion effects when repairs are also considered in addition to other parameters already modeled in (7). This resulted in the formulation of (8) for the 'second' erosion below:

$$
\begin{array}{r}
\xi=\boldsymbol{S}_{c}-p \text { or } \\
\xi=\frac{\eta t^{2}+\beta t-\gamma}{\varphi}
\end{array}
$$

where $\eta=\alpha q$

$$
\begin{gathered}
\beta=\alpha^{2}+\alpha q-k k_{e} c_{i} \tau \tau_{c}^{2} \\
\gamma=k \tau_{c}^{2} \\
\varphi=\tau_{c}(t+1)\left(1+k_{e} c_{i} \tau t\right)
\end{gathered}
$$

Equation (8) has a quadratic numerator which was solved when $\xi=0$ with an assumption that repairs were just made. It was a time lag noted before the erosion effect arises according to this formulation. It also depended on the values of $k$ and $\alpha$ on top of other factors embedded in the original formulations. Therefore, equation (10) below was solved for values of $t$ using the already calculated values in [6], [7] as seen in Table VIII below.

$$
\eta t^{2}+\beta t-\gamma=0
$$

TABLE VIII: TIME REQUIREMENTS NECESSARY FOR $\xi=0$

\begin{tabular}{cccccc}
\hline$\alpha\left(m^{2}\right)$ & $k$ & $\eta$ & $\beta$ & $\gamma$ & $t(\mathbf{s})$ \\
\hline 0.0213 & 0.004 & 0.0749 & -76.0363 & -0.1291 & 704 \\
0.00138 & 0.0007 & 0.00485 & 177.2809 & 0.0226 & 2744 \\
\hline
\end{tabular}

The variations to manage the time effects for the other parameters were done in the original experiment formulations though they may look constants for this evaluation. However other variations in time were considered in the analysis. The evaluations are summarized in Table IX. Similarly, equation (8) was evaluated for various values of $\xi$ and a varying $t$ up to three rain months $(486,000 \mathrm{~s})$ for average of $5400 \mathrm{~s}$ per rain day. See Table IX for only the rill evaluation for this formulation.

TABLE IX: EVALUATION OF $\xi$ WITH A VARYING $T$ FOR THE RILL CASE FOR A A PARTICULAR EXPERIMENT SPOT

\begin{tabular}{llll}
\hline$\alpha\left(m^{2}\right)$ & $k$ & $t(\mathbf{s})$ & $\xi\left(\boldsymbol{m}^{3} / \mathbf{k g}\right)$ \\
\hline $\mathbf{0 . 0 2 1 3}$ & 0.004 & $5.40 \times 10^{3}$ & $1.8 \times 10^{-3}$ \\
& & $1.62 \times 10^{5}$ & $5.4 \times 10^{-2}$ \\
& & $2.43 \times 10^{5}$ & $8.1 \times 10^{-2}$ \\
& & $4.86 \times 10^{5}$ & $1.6 \times 10^{-10}$ \\
$\mathbf{0 . 0 0 1 3 8}$ & 0.0007 & $5.40 \times 10^{3}$ & $9.1 \times 10^{-5}$ \\
& & $1.62 \times 10^{5}$ & $2.7 \times 10^{-3}$ \\
& & $2.43 \times 10^{5}$ & $4.1 \times 10^{-3}$ \\
& & $4.86 \times 10^{5}$ & $8.2 \times 10^{-2}$ \\
\hline
\end{tabular}

\section{DISCUSSION}

It was noted that the repair factor increases with decreasing time that was necessary that was necessary to take action for repairs as earlier illustrated in Table IV and Table VII above. More so, destruction on the road could be gauged by the use of the model and its underlying calculations like shear stress. Similarly, the repair factor was also modeled in such a way that a given level of compaction was suggested for a given destruction within a limited and given time. For instance, form Table IV and Table IX, an increasing repair factor reduces the erosion effect in such a way that an increase of $50 \%$ in $\mathrm{p}$, reduces the erosion factor by $33 \%$ in 30 rain days. This also depended on the initial affected area $\alpha$ and $\tau_{c}$ together with other factor that affect erosion on roads. Also noted was that the bigger the initial effect $\alpha$, the larger the repair factor required for a given rain period.

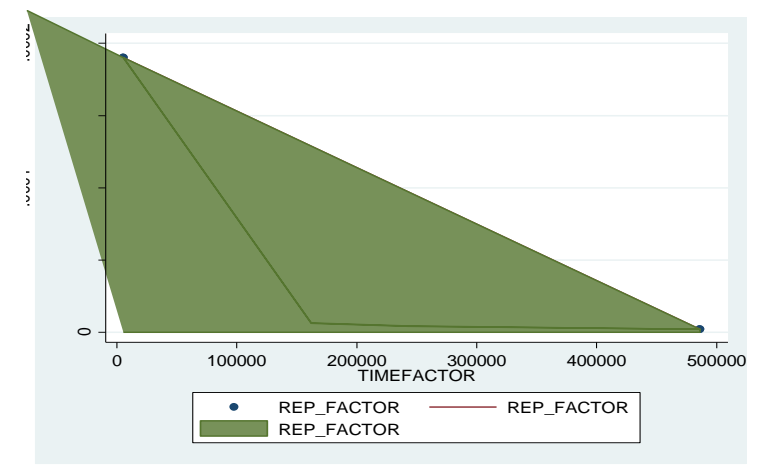

Fig. 1. Area-scatter relation for $p$ and $\mathrm{t}$ for rill results.

Results from Table VIII showed that bigger $k$ values gave 
rise to bigger $p$ factor. This was because the necessary repairs were modeled such that the $k$ values have a chance to influence as to when to engage a repair or not. Therefore depending on the on the baseline measurements, where such basic variables are calculated, a better prediction can be made on road repairs. Further, simple regression analysis of these results showed that on average, $p$ has 20.5 more of the $k$ value needed for the time factor requirement to manage some destruction for the experiment spot taken. This was also illustrated by the graphs below:

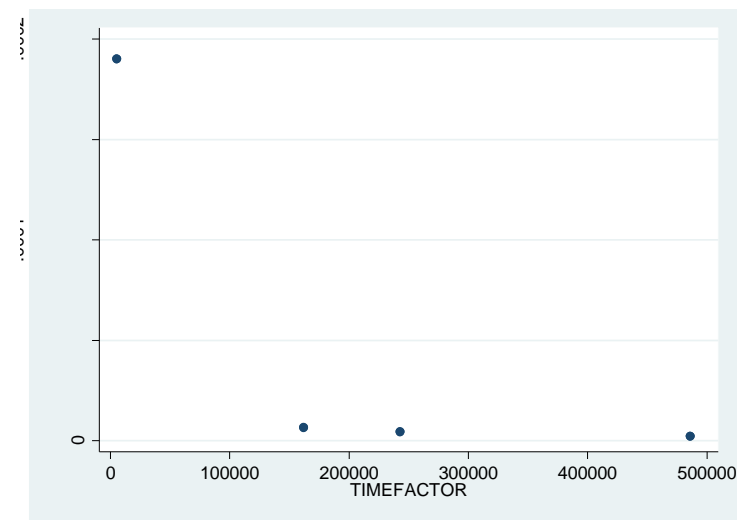

Fig. 2. A scatter plot for $p$ on $t$ for rill results.

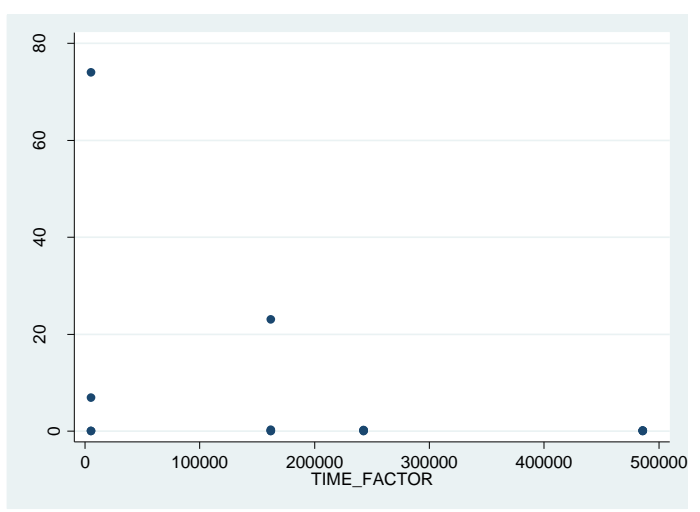

Fig. 3. Scatter graph for $p$ and $t$ for dune results.

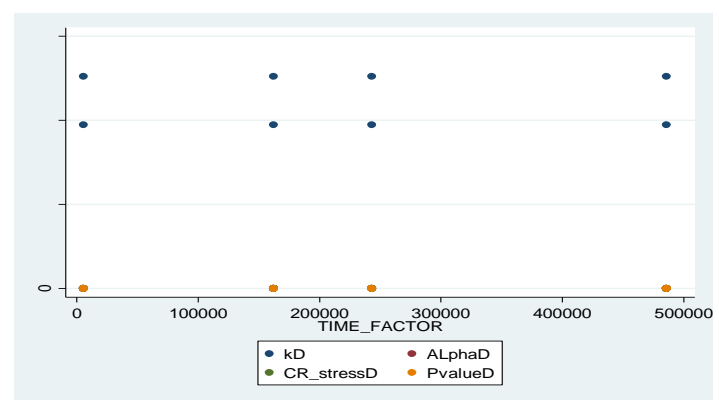

Fig. 4. Scatter relations for other variables in relation to time for dune results.

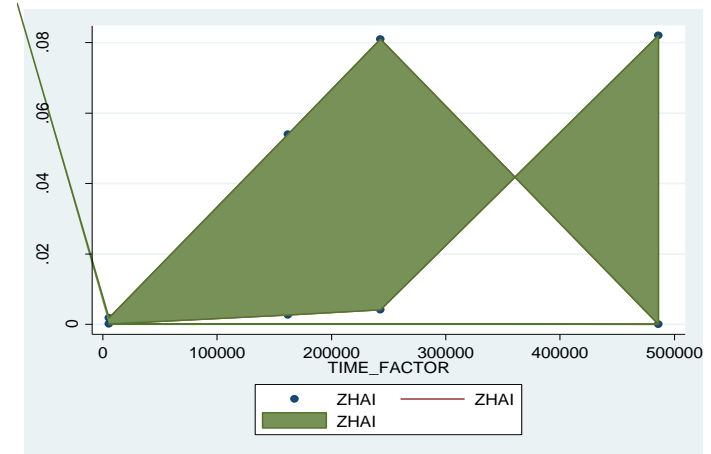

Fig. 5. Areallinear-scatter relations between $\xi$ and $t$ for the rill case.
These figures emphasize the fact that the destruction brought about by the development of rills and dunes is inversely proportional to the repair factor requirement necessary to neutralize the effects. On the other hand, they showed that the bigger the erosion destruction, the less the time that was required to engage an action for maintenance or repair.

\section{CONCLUSION AND RECOMMENDATIONS}

'Second' erosion on gravel or dirt roads was modeled in order to predict the effects caused by rills and dunes development along the drainage paths of such roads affected by some erosion. The study results show that the approximate time required for road repairs, given a remarkable effect, reduces with the size of the initial effect. Results further show that erosion effects resulting from rill or dune development effects are tremendously reduced.

The study strongly recommends that more of scientific procedures and approaches should be employed to manage erosion on roads than just mere observational methods. Parameters involved in erosion effects are measured earlier in time and repairs are managed depending on the measured values. Although the model may have drawbacks, like fixing some variable parameters and managing the variations through the basic parametisation measurements, the model still gives reliable evaluations.

Erosion on gravel roads may bring serous impacts that include among others: road size reduction, road gorging, and road mudding-ripples. The models suggested some solutions that include proper ditching for better surface drainage and minimized initial effects as developing rills and dunes is necessary. Proper maintenance than crude and fast-move repairs can check on the deterioration of non-paved roads especially in rainy seasons. UNRA and other road repair authorities can also use maps of the observed damages over time in order to manage expected damages. These can help in the preparation of maintenance schedules. It will also allow for better decision making, faster repairs, safe roads, and economic effectiveness [19].

The history of each road segment should be studied for a précised reason for the delays between damage by dunes or rills and repairs. Similarly, proper, recommended and enough crowning and compaction should be done whenever repairs are being implemented. In fact a proper well-drained road should have a crown. Poor crowning saves water collection on the road surfaces which would otherwise develop in to potholes [20]. These are one of the most destructive features on Uganda's gravel road surfaces.

\section{ACKNOWLEDGMENT}

This work Erosion Features on Roads in Uganda-Formation and Effects" was supported in part by Makerere University through the Sida Grant, Sweden.

\section{REFERENCES}

[1] B. Yu. "A unified framework for water erosion and deposition equations," Soil Sci. Soc. Ann. J., vol. 67, pp. 251-257, May, 2001.

[2] R. K Misra and C. W. Rose, "Application and sensitivity analysis of process-based erosion model," J. Soil Sc., vol. 47, no. 4, pp. 593-604, 1996. 
[3] K. Santosh, Irrigation Engineering and Hydraulic Structures, 21st ed., Khanna Publishers, 2007, pp. 95-544.

[4] C. T. Yang, "Potential energy and sediment transport," Water Resources, ch. 7, pp. 312-322, 1971.

[5] T. Semwogerere, S. B. Kucel, and P. O. Lating, "An analysis of existing erosion and deposition models," in Proc. $2^{\text {nd }}$ Conf. Engineering and Technology, Entebbe, 2011, pp. 677-683.

[6] T. Semwogerere, S. B. Kucel, and P. O. Lating. "Modeling erosion from erosion features on gravel roads- the rill model," in Proc. Annиal conf. Engineering and Technology, Singapore, 2014, pp. 637-642.

[7] T. Semwogerere, P. O. Lating, and S. B. Kucel, "Duning in rills on unpaved roads in Uganda," J. Advances in Mathematics, vol. 6, no. 3, pp. 1038-104, Feb. 2014

[8] BS 1377, Method of Testing Soil for Civil Engineering Purpose, British Standard Institute, BSI, London, England, 1990, pp. 1-15.

[9] BS 1924, Method of Test for Stabilized Soils, British Standard Institute, BSI London, England, 1990, pp. 3-10.

[10] R. P. C. Morgan, J. N. Question, R. E. Smith, G. Govers, J. W. A. Poesen, K. Averswald, G. Chisci, D. Torri, and M. E. Styczen, "The European Soil Erosion Model (EUROSEM): A dynamic approach for predicting sediment transport from fields and small catchments," Earth Surface Processes and Landforms, 1998, ch. 23, pp. 527-544.

[11] C. B. Nyle and R. W. Ray, The Nature and Properties of Soil, 14th ed., Pearson Prentice Hall, 2008, ch. 2.

[12] L. C. Rijn, Principles of Sediment Transport in Rivers, Estuaries, and Coastal Seas: Fluvial and Sediment Properties, Aqua Publications, 1993, ch. 3.

[13] K. Santosh, Irrigation Engineering and Hydraulic Structure, 21st ed. Khanna Publishers, 2007, pp. 95-544.

[14] E. A Kamal, "Physical properties of sediment particles,"presented at Conf. Engineering Mathematics, Santa Fe, 2009.

[15] Roadway Width Specifications, Road Design Manual, Uganda National Roads Authority (UNRA), 2008, pp. 3.

[16] D. Narayan, R. Patel, A. Rademacher, and S. Koch-Schulte. (March, 2000). On the voice of the poor: Can anyone hear us? World Bank\& Oxford University Press. [Online]. 1(1). p. 360. Available: http://www.amazon.com/Can-Anyone-Hear-Us-Publication/dp/01952 16016.

[17] Answers to Frequently Asked Questions about Gravel Roads, Franklin Regional Council of Governments, A report prepared under contract 31024 in cooperation with the Massachusetts Highway Department and the U.S. Department of Transportation, Federal Highway Administration, 2001, pp. 3-11.

[18] T. E. Croley, "Unsteady overland flow sedimentation," J. Hydrol. Amsterdam, vol. 56, pp. 325-346, April 1982.
[19] T. Seidler, M. Mihola, and D. Cihlarva, "Analysis of road repairs in undermined areas," World Academy of Science and Technology, vol. 5, no. 12, pp. 374-377, May, 2011.

[20] T. Semwogerere, P. O. Lating, and S. B. Kucel, "Erosion features on gravel roads in Uganda- formation and effects," in Proc. $2^{\text {nd }}$ Annual Conf. Engineering Mathematics and Physics, Colombo, 2013, pp. $175-181$.

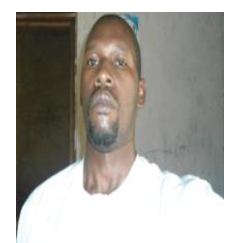

Twaibu Semwogerere was born in August, 1973, and holds a bachelor of science education degree (1995) (mathematics), and master of science degree (2002) (applied mathematics) of Makerere University, Kampala, Uganda. He has a work experience of over 20 years in colleges and university teaching. He had published several papers, the previous one being: "Duning in Rills on Unpaved Roads in Uganda", 2014 in the Journal of Advances in Mathematics. He is currently a Ph.D student (engineering mathematics) in the College of Engineering Design, Art, and Technology (CEDAT), Makerere University and a lecturer at Busitema University. His areas of research and teaching include stochastic processes, probability theory, and numerical analysis.

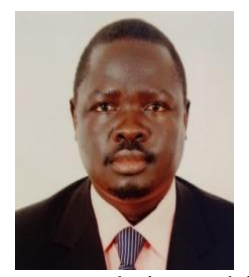

Samuel Baker Kucel holds a $\mathrm{PhD}$ in mechanical engineering (energetics) from the University of Udine (2002, Italy) and a master of engineering science in Mechanical Engineering from The University of New South Wales (1998, Sydney). Dr. Kucel has strong industrial and consulting experience, especially in the areas of mechanical systems design and implementation, fluid systems design, thermal systems design and implementation, energy efficiency, renewable energy technologies, and planning and development of power projects. he has vast experience in university lecturing/teaching, research, administration, mentorship and outreach. He is currently the deputy vice chancellor in charge of Academic Affairs and Research, Busitema University.

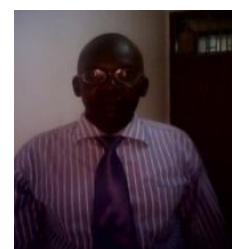

Peter Okidi Lating has doctorate degree in technology (Makerere University), and Techno-Science studies (BTH). He is currently a senior lecturer in the Department of Electrical and Computer Engineering, Makerere University. His research interests are in techno science studies, engineering mathematics, and cluster development. 